\title{
TERNO DE REIS: ENTRE A TRADIÇÃo E A ATUALIZAÇÃo DA IDENTIDADE NA COMUNIDADE QUILOMBOLA NOVA ESPERANÇA
}

\author{
Cledineia Carvalho Santos \\ Etnomídia - Pesquisa em mídia e etnicidades, Faculdade de Comunicação, Universidade Federal da Bahia, Brasil
}

\begin{abstract}
RESUMO
O presente artigo busca analisar como a festa de Reis, uma expressão cultural presente em diversas comunidades brasileiras, neste caso, na Comunidade Quilombola Nova Esperança, município de Wenceslau Guimarães, Bahia, mantém a tradição perante as diversas influências culturais oriundas das identidades móveis contemporâneas. A partir de narrativas dos participantes do Terno de Reis, o folguedo é importante elemento na reafirmação da identidade local e, sobretudo, dos laços de ancestralidade comum com o fundador da comunidade. Ao discutir a dinâmica que envolve todo o festejo da festa de Reis, torna-se pertinente pesarmos a cultura como algo dinâmico, vivo no tempo e no espaço, se (re)significando e avivando a memória do povo que possui relação contínua entre passado e presente. As narrativas apresentam ainda a preocupação com a permanência da festa diante das eminentes ameaças que o folguedo sofre face à liquidez das relações sociais contemporâneas.
\end{abstract}

\section{Palavras-chave}

Terno de Reis; cultura; identidade; Nova Esperança

\section{TERNO DE REIS: BETWEEN TRADITION AND AN UPDATE ON IDENTITY IN THE QUILOMBOLA COMMUNITY OF NOVA ESPERANÇA}

\begin{abstract}
This paper aims to analyze how Three Kings day, a cultural expression present in several Brazilian communities, in this case the Quilombola Community of Nova Esperança, municipality of Wenceslau Guimarães, Bahia, keeps tradition regardless of the various cultural influences from contemporary shifting identities. According to the narratives of participants in Terno de Reis, the celebration is an important element in the reaffirmation of local identity and, above all, of the bonds of common ancestry with the founder of the community. When discussing the dynamics that involve the whole celebration of Three Kings day, it becomes pertinent to weigh culture as something dynamic, alive in time and space, capable of (re)acquiring new meanings and re-igniting the memory of the people who have a continuous relationship with both the past and the present. The narratives also show concern for the survival of this celebration in the face of the eminent threats that it suffers as a result of the liquidity of contemporary social relationships.
\end{abstract}

KEYWORDS

Terno de Reis; culture; identity; Nova Esperança 


\section{INTRODUÇÃo}

No presente trabalho nos comprometemos discutir sobre a festividade do Terno de Reis na Comunidade Quilombola Nova Esperança, situada na zona rural do município de Wenceslau Guimarães, estado da Bahia, Brasil, a partir dos elementos que o caracterizam como atividade tradicional e cultural do lugar e de como este folguedo convive com elementos da modernidade que o afetam.

Percebendo que os festejos do Terno de Reis na referida comunidade apresentam elementos tradicionais oriundos da época do surgimento, ao tempo que são inseridos outros ao longo dos anos, buscamos analisar como os sujeitos que o compõem se relacionam com os elementos da modernidade inseridos continuamente devido às influências de outros sujeitos que se movem entre a comunidade e outros espaços, especialmente a cidade grande, numa notória relação entre tradição e modernidade.

Ao longo do artigo apresentamos um breve histórico sobre a origem do Terno de Reis, onde concluímos que o mesmo surge em Portugal por volta do século XIV e, ao se difundir, absorveu elementos teatrais europeus. O mesmo chegou ao Brasil logo após o processo de colonização na região Nordeste do país.

A fim de localizar o folguedo em análise, trouxemos um breve histórico da Comunidade Quilombola de Nova Esperança, assim como pincelamos sobre o conceito de quilombo, tanto no âmbito antropológico, quanto na perspectiva jurídica contemporânea.

A metodologia utilizada foi a história oral por ser próxima da etnografia, visto que em paralelo às entrevistas houve observação e registro dos acontecimentos durante o período da festa. É importante salientar que a metodologia utilizando fontes orais possibilita que os sujeitos historicamente invisibilizados possam falar por si mesmos, enquanto testemunhas dos fatos e, assim, registrar sua memória.

O artigo apresenta e valoriza a existência e (re)existência de comunidades tradicionais no Brasil a partir de elementos culturais marcadores da memória, neste caso, o Terno de Reis, especialmente em tempos de incertezas para os povos que historicamente foram sucumbidos pelo statu quo de quem já tem sua história de certo modo registrada nos livros oficiais.

\section{PerCuRso metodológico}

Este trabalho é de natureza interpretativa, cuja metodologia é a história oral, por meio de entrevistas com integrantes da comunidade Quilombola de Nova Esperança que compõem o grupo do Terno de Reis, a fim de compreender seu entendimento sobre a importância da manutenção do coletivo como afirmação da identidade do quilombo. Conforme Alberti (2005),

a História Oral é uma metodologia de pesquisa e de constituição de fontes para o estudo da história contemporânea surgida em meados do século $\mathrm{XX}$, após a invenção do gravador à fita. Ela consiste na realização de entrevistas gravadas com indivíduos que participaram de, ou testemunharam 
acontecimentos e conjunturas do passado e do presente. (Alberti, 2005, p. 155)

Nesse sentido, a história oral, como procedimento metodológico, busca perpetuar as vivências de sujeitos que ao compartilhar percepções de si também falam de seu entorno, mesmo que involuntariamente.

Salientamos que a pesquisa com a história oral procura buscar verdades e não uma verdade absoluta, totalizante. Por isso, ao ouvir os sujeitos comuns articulam-se as narrativas de uma história em que estes se apresentam e representam outros sujeitos com quem em algum momento tiveram contato, construindo e reconstruindo a memória coletiva.

As entrevistas se deram com quatro integrantes do Terno de Reis durante os dias dos festejos em janeiro de 2016. Para preservar a identidade dos sujeitos, os mesmos são tratados por colaboradores. Cada colaborador pôde falar livremente sobre a sua percepção em torno dos festejos com duração que variou entre 30 minutos e uma hora. Durante as gravações, os pesquisadores não intervieram com perguntas ou direcionamentos. Assim foi possível registrar não apenas as falas, mas gestos e pausas. Para Alberti

o conhecimento prévio do objeto de estudo é requisito para a formulação de qualquer projeto de pesquisa. No caso da história oral, dele dependem as primeiras escolhas que devem ser feitas no encaminhamento da pesquisa: que pessoas entrevistar, que tipo de entrevista adotar e quantas pessoas ouvir. (Alberti, 2005, p. 32)

Em síntese, o método e as técnicas utilizados na pesquisa contribuíram para a recuperação da memória vivida e a percepção sobre os efeitos do contemporâneo nas festividades do Terno de Reis pela ótica dos sujeitos que vivenciam as atividades culturais da Comunidade Quilombola Nova Esperança.

\section{A FeSTA de REIS no QUILOMBo: IDENTIDADE COMO RESISTÊNCIA}

Como símbolo do amanhecer, a festa de Santos Reis é comemorada no dia seis de janeiro, data em que o menino Jesus se manifestou aos gentios e quando foi revelada ao mundo a vinda do Messias. Esta celebração, trazida pelos colonizadores portugueses, faz parte da herança cultural do povo brasileiro. É uma festa popular folclórica, que por meio da tradição e da memória se mantém viva entre as comunidades tradicionais do Brasil profundo, e que não aparece nos escritos oficiais da história.

É importante considerar que a escravidão no Brasil marcou a história de forma negativa, deixando marcas na memória do povo negro que a duras penas resistiu à sentença de sofrimento imposta pela servidão. Para superar o sofrimento se abraçaram em coletivos, como os quilombos, lugar onde resistiram a todo tipo de opressão.

Nesse contexto, o quilombo tornou-se um local de empoderamento identitário, reavivando as lutas políticas através do processo de resistência, assegurando o direito fundamental de "existir" desses seres humanos que foram (des)humanizados, pelo desejo de superioridade racial. 
Os quilombos no Brasil são resultantes da história da escravidão negra no país. Para Munanga e Gomes (2006, p. 11), a história da escravidão é marcada por diversos atos de luta e coragem e os quilombos são uma dessas marcas da resistência negra. Assim, os quilombos surgiram como "estratégias de oposição, a uma estrutura escravocrata pela implementação de uma forma de vida, de uma outra estrutura política na qual se encontraram todos os tipos de oprimidos".

Surgido no período colonial, o quilombo tem se modificado de acordo com o contexto e as relações estabelecidas ao longo dos anos. Por isto, não se restringe apenas a lugar de negros fugidos, conforme ficou reconhecido por mais de um século após a promulgação da Lei Áurea de 1888, que oficializou o fim do trabalho escravo no Brasil, mas, também, como todo agrupamento oriundo das resistências ao regime escravagista. $O$ quilombo simboliza a expressão da luta de classes no período escravagista contra o sistema opressor, "quer no seu sentido econômico quer na sua significação social, o escravo fugido era um elemento da negação da ordem estabelecida" (Moura, 1981, p. 269).

Clóvis Moura (1981) trata o quilombo enquanto lugar de resistência, na perspectiva da organização política de homens que fugiam da situação de opressão. Para este pesquisador, era considerado quilombo qualquer forma de agrupamento em oposição à escravidão.

O quilombo foi, incontestavelmente, a unidade básica de resistência do escravo. Pequeno ou grande, estável ou de vida precária, em qualquer região em que existia a escravidão, lá se encontrava ele como elemento de desgaste do regime servil. (...) O quilombo aparecia onde quer que a escravidão surgisse. Não era simples manifestação tópica. Muitas vezes surpreende pela capacidade de organização, pela resistência que oferece; destruído parcialmente dezenas de vezes e novamente aparecendo, em outros locais, ... O quilombo não foi, portanto, apenas um fenômeno esporádico. Constituía-se em fato normal dentro da sociedade escravista. Era reação organizada de combate a uma forma de trabalho contra a qual se voltava o próprio sujeito que a sustentava. (Moura, 1981, p. 87)

A questão quilombola é complexa, visto que cada quilombo tem histórias distintas, não sendo apenas um reduto de negros fugidos. Uns são resultado de compras de terras por escravizados forros, outros de terras herdadas dos antigos senhores em falência.

Apesar das diversas origens, há a convergência da escravidão - por isso, existem definições distintas em torno da questão como "terras de pretos"', "remanescentes de quilombos", "comunidade quilombola"2 e "comunidades negras, rurais e ou urbanas"3. Segundo Arruti (2008), os quilombos não são isolados e nem todos têm origem na rebeldia

\footnotetext{
'O termo é o mais utilizado pelos estudiosos por considerarem ser expressão nativa, e não uma denominação importada historicamente, entre os quais se destacam Alfredo Wagner Berno de Almeida (2006), Renato Queiroz (1983/2006) e Neusa Maria Mendes de Gusmão $(1979,1995)$.

${ }^{2}$ Conceito impresso por Almeida (2011).

${ }^{3}$ O termo é mencionado no Artigo 68 do ADCT (Ato das Disposições Constitucionais Transitórias da Constituição Federal de $1988,321 w)$.
} 
e tampouco definidos pela densidade demográfica. Nesse sentido, são considerados quilombos "grupos que desenvolveram práticas de resistência na manutenção e reprodução de seus modos de vida característicos num determinado lugar" (Arruti, 2008, p. 2).

Entende-se que os quilombos foram se ressignificando ao longo do tempo, assim, o termo também foi modificado a fim de atender as demandas atuais. Sobre isto, a Constituição Federal de 1988, no Art. 68, no Ato das Disposições Constitucionais Transitórias, passa a considerar quilombo toda a área ocupada por remanescentes dos antigos quilombos.

Almeida realça que "o novo significado expressa a passagem de quilombo, enquanto categoria histórica e do discurso jurídico formal, para um plano conceitual construído a partir do sistema de representações dos agentes referidos às situações sociais assim classificadas hoje" (Almeida, 2011, p. 47). Ou seja, o termo quilombo carrega em suas entranhas muito mais que uma definição meramente histórica e representa um amplo conceito que perpassa pelas subjetividades de cada grupo nas pautas pela busca de direitos, seja de território, seja de identidades.

Desse modo, o conceito quilombo foi ampliado para atender ao maior número possível de afrodescendentes, e não necessariamente como um lugar de movimentos de rupturas à escravidão, mas a outros grupos de pessoas que de alguma maneira tenham vínculos com este período e buscaram consolidar-se em um território com identidades e representações culturais próprias.

O reconhecimento de comunidades quilombolas remanescentes surge como reparação aos danos históricos causados aos povos escravizados e que ainda hoje lutam pelo seu reconhecimento identitário e reivindicam sua cidadania.

Nesse contexto, a comunidade de Remanescentes Quilombolas de Nova Esperança em Wenceslau Guimarães, cidade do Baixo-Sul do estado da Bahia, na região Nordeste do Brasil, apresenta-se como símbolo de resistência da cultura e oralidade de um povo que mantém nos seus lábios toda uma sabedoria, vivência e amor pela religiosidade.

O Terno de Reis de Nova Esperança surge concomitantemente com a chegada do desbravador do lugar, o Sr. Faustino dos Santos que, segundo a história contada oralmente pelos moradores mais antigos, veio de muito longe, Canudos, trazendo consigo, mulher, filhos e a Santa protetora dos pretos, Nossa Senhora do Rosário.

O Senhor Faustino dos Santos, apesar de muito religioso, gostava de festa. Assim, o Terno de Reis passou a ser a extensão dos ritos religiosos no intuito de entreter os foliões até ao raiar do dia.

\section{O Terno de Reis: de Portugal para o Brasil}

A Folia de Reis ou Terno de Reis caracteriza-se por ser uma festividade do "catolicismo popular" que reproduz a história dos Três Reis Magos e sua jornada até o local do nascimento de Jesus. Os festejos ocorrem em vários locais do Brasil, especificamente de 24 de dezembro a 6 de janeiro.

Durante esses dias os foliões fazem visitas às casas, realizam cantos, tocam instrumentos, rezam, dançam e sambam. A folia de reis exerce importante influência em 
vários lugares do interior do Brasil. Na maioria dos lugares, no dia 6 de janeiro acontece o desfecho do ritual religioso com muita festa, o dia de Santos Reis.

O Terno de Reis teve origem em Portugal no século XIV, mas foi reconfigurado e divulgado em toda Europa a partir do século XVI. Absorveu elementos do teatro português, dos boêmios e estudantes medievais. Pelo seu caráter colorido e uso de instrumentos musicais variados, acredita-se que o contato com os ciganos também colaborou para a divulgação do folguedo tal como o conhecemos atualmente.

Atribuiu-se as origens da Folia a costumes medievais: mestres, estudantes, boêmios, mendigando e se divertindo percorreram por três séculos, do XII ao XIV, toda a Europa. Em outra versão, os ciganos são apontados como possíveis raízes dessa prática cultural, não só pelo seu nomadismo, mas também pelos instrumentos, estandartes, fitas e flores coloridas que os caracterizam. França, Inglaterra, Bélgica, Alemanha, Itália, Espanha e Portugal, entre outros, festejavam os três Reis Magos na época de Natal. O Presépio e os Autos Natalinos já eram conhecidos desde o século XIV em Portugal, mas as primeiras notícias da Folia, tal como a conhecemos hoje, remontam ao século XVI. (Machado, citado em Gonçalves, 2008, p. 6)

Sobre estes festejos espalhados e reinventados em tantos lugares no Brasil, estudos historiográficos apontam que o "Terno de Reis" tem marcador cultural tradicionalmente católico e chegou ao Brasil ainda no período da colonização portuguesa. Em seus estudos, Pergo afirma:

A tradição da "Folia de Reis" teria chegado ao Brasil por intermédio dos portugueses no período da colonização, uma vez que essa manifestação cultural era realizada por toda a Península Ibérica sendo comum a doação e recebimento de presentes a partir da entoação de cantos e danças nas residências. Nessa linha de argumentação, a Folia de Reis teria surgido no Brasil no século XVI, por volta do ano de 1534, por meio dos Jesuítas, como crença divina para catequizar os índios e posteriormente os negros escravos. (Pergo, s.d., p. 1)

\section{Segundo o Instituto do Patrimônio Histórico e Artístico Nacional:}

a Folia de Reis, considerada uma das mais belas manifestações populares do Brasil, é uma festa de origem portuguesa. Chegou ao país por volta do século XVIII, inspirada na tradição católica da visita dos três Reis Magos ao menino Jesus. Na cultura tradicional brasileira, os festejos de Natal eram comemorados por grupos que visitavam as casas tocando músicas alegres em louvor aos Santos Reis e ao nascimento de Jesus. Esta tradição ganhou visibilidade, especialmente no século XIX, e se mantém viva e atuante em grande parte do país. (IPHAN) ${ }^{4}$

4 IPHAN - Instituto do Patrimônio Histórico e Artístico Nacional. Retirado de http://portal.iphan.gov.br/pagina/ detalhes/989. 
Para Gonçalves (2008), no Brasil, a Folia de Reis faz-se presente desde o início de sua colonização. O primeiro indício é a data de fundação do "Forte dos Reis Magos" em Natal (RN): "uma prova desta presença é o fato de o Forte dos Reis Magos, em Natal (RN), ter sido fundado em seis de janeiro de 1598, marcando a introdução do culto aos Santos Reis ainda no século XVI" (Gonçalves, 2008, p. 6).

Outra evidência é que os Jesuítas utilizavam símbolos para catequizar os indígenas.

A folia, como a música e o drama, foi usada pelos jesuítas para a catequese. Os padres Manoel da Nóbrega e José de Anchieta usavam a folia e outras danças nas procissões e nos autos, muitos escritos na língua geral. Com a consolidação da colonização, os rituais usados na catequese do índio disseminaram-se entre colonos portugueses, negros escravos e mestiços de toda sorte e foram incorporados nas festas dos padroeiros. (Rios, 2006, p. 3)

Ao longo dos séculos a Folia de Reis no Brasil se reconfigurou, incorporou novos elementos e atualmente cada manifestação deste evento tem características próprias de cada localidade. A Folia de Reis, na forma como acontece nas comunidades, é carregada de elementos característicos da cultura local numa íntima relação entre o sagrado e o profano e reunindo manifestações do seu universo multicultural.

No Brasil, os festejos de Reis acontecem na visitação às casas pelos reiseiros que chegam tocando instrumentos de percussão e canções de repertório popular, conhecidas em Nova Esperança como cantorias de Reis, cuja letras são de fácil assimilação, como esta cantada nos festejos de Nova Esperança no momento em que os foliões pedem permissão para o dono da casa recebê-los:

Ô de casa, ô de fora

Maria vai vê quem é

São os cantador de reis

Quem mandou foi São José (bis).

A exemplo desta cantiga, outras cantorias vão surgindo durante a folia que repetida infinitas vezes forma um coro ao som dos pandeiros e palmas. Ao longo dos anos, além das tradicionais canções, outras são criadas pelos próprios foliões, cujas letras atendem as experiências culturais da comunidade, como esta que se refere ao contexto da cacauicultura.

Cacau é boa lavra, eu vou colher

$\mathrm{Na}$ força do verão, eu vou vender

Cacau é boa lavra!

Cacau é boa lavra, assim diz o lavrador

Cacau é boa lavra!

Cacau de 150 (cento e cinquenta)

Muitos homens enricou!

Cacau é boa lavra 
Assim diz o lavrador!

Quem vende cacau tem dinheiro e tem valor.

Durante o decorrer da festa os foliões saem de casa em casa e, neste movimento, o dono da casa puxa o "samba de despedida" dando sinal que é chegada a hora de seguir para a visitação em outras moradas. Esse sinal é dado cantando:
Nosso Terno se despede
O Santo Reis já vai embora
Fica Deus na sua casa
Vamos com Nossa Senhora

As cantigas abordam temas diversos, sendo muitas de caráter religioso do catolicismo popular, transmitido oralmente. Muito provavelmente, parte delas foram trazidas pelos fundadores da comunidade. Outras já apresentam temáticas locais, como é o caso da música de trabalho sobre a cultura do cacau.

Também entoam cantigas que abordam as relações entre homens e mulheres como esta:

Ô mulher, ô mulher!

Eu vou no samba, vou já!

Se o samba lá tiver bom

Eu vou e venho te buscar!

As festas aos Reis em cada lugar agregam elementos culturais característicos e identitariamente marcados e, no caso do Brasil, esta festa é a junção do catolicismo e dos ritos das religiões de matrizes africanas. Nas comunidades de remanescentes quilombolas ela vem se afirmando como bem imaterial para as políticas afirmativas das identidades locais.

O Terno de Reis, ao chegar no Brasil, ganhou força e se constitui uma tradição em vários lugares do país, sobretudo nas pequenas cidades e nos territórios do interior destas, como é o caso do local aqui apresentado.

\section{O Terno de Reis em Nova Esperança}

Nova Esperança é uma comunidade de remanescentes quilombolas, localizada na zona rural do município de Wenceslau Guimarães, Baixo Sul da Bahia. A comunidade tem origem em 1929, com a chegada do fundador Faustino dos Santos, sua companheira Antônia Maria de Jesus e seus oito filhos. Ali estabeleceram moradia, enfrentaram e venceram as adversidades na busca de melhores condições de vida. Nesta empreitada trouxeram consigo heranças culturais e religiosas adquiridas nas relações construídas em suas vidas pregressas.

A comunidade guarda até os dias atuais rituais ligados aos ancestrais fundadores, dentre estes o Terno de Reis. Com origem no catolicismo popular, os festejos de Reis em 
Nova Esperança agregam elementos culturais diversos, numa relação entre o sagrado e o profano. A festa de reis tem importante influência na ressignificação da comunidade enquanto espaço de resistência do povo de quilombo.

Em Nova Esperança, o Terno de Reis acontece de 24 de dezembro a 6 de janeiro, com todos os ritos direcionados ao nascimento do Menino Jesus, relembrando a visita dos três Reis Magos. Durante esses dias na comunidade fazem-se cultos na igreja local e visitam-se as casas, tendo o grande ápice no dia 6 de janeiro, no qual os participantes fazem apresentações na igreja e posteriormente saem visitando os moradores. No último dia, os moradores fazem apresentação teatral onde entoam cantos religiosos e leituras bíblicas.

O grupo do terno é composto por 12 cantadores, quatro personagens representando a parte religiosa, sendo os Três Reis Magos e o Menino Jesus, e um porta-bandeira. Além destes personagens caracterizados, a participação da comunidade confunde-se com o folguedo, visto que todos se envolvem, da organização à festa.

Para a apresentação, as pessoas usam indumentárias bastante coloridas, com fitas e bandeiras, e alimentos que cada morador leva e compartilha durante o evento. Após esse momento, entoam os primeiros cantos com uso de instrumentos musicais como triângulos, sanfonas, pandeiros, pífanos e muitas palmas. Com muita alegria e cantigas de roda os cantadores de reis tocam instrumentos e sambam. Ao final, o morador retribui a visita com muita comida e bebidas.

Após visitar todas as casas, os cantadores de Reis finalmente chegam à praça central, localizada em frente da igreja, e continuam os festejos com muita comida, bebida, samba e cantoria, em ambiente festivo até o raiar do dia.

Embaixo da árvore de amêndoa uma grande mesa é posta para a confraternização entre todas as pessoas que estão presentes. Os alimentos são feitos pelos moradores de forma espontânea. Cada família oferece o que pode e deseja. A mesa é composta por pratos doces como: canjica, cocadas, bolos assados em palhas de banana, bolos de milho, mungunzá; ao raiar o dia é servida a feijoada da comunidade feita pelas mulheres na associação de moradores.

A festa tem um misto do sagrado e do profano. No campo do sagrado está a festa na igreja local que celebra a festa da visitação do Três Reis Magos ao Menino Jesus. $O$ profano acontece logo após o ato na igreja quando os integrantes do coletivo saem em visitação com suas indumentárias e tocando instrumentos artesanais, como tambores, pandeiros e sanfonas, que seguidos por todos vão até às casas com o presépio onde pedem licença para entrar. Dando sequência aos festejos, sambadores e foliões saem da casa puxando o "samba de despedida" e se direcionam para a próxima casa.

O festejo aos Santos Reis está intimamente ligado ao pertencimento dos sujeitos que vivem a comunidade. Conforme nos foi dito por uma das entrevistadas: "o terno é, para nós, a vida da nossa comunidade. Indo de casa em casa a gente se diverte, samba, bebe um vinhozinho. Tem sempre umas comidas. Vou dizer, é só alegria aqui pra nós" (Colaboradora 3, 70 anos, entrevistada em 2015). 
Há um construto histórico em torno da memória dos moradores mais velhos da comunidade. Para estes, a festa se confunde com a história afetiva do lugar, visto que a mesma serviu de elemento de referência para o reconhecimento do lugar, enquanto remanescentes quilombolas.

Esta percepção, tanto histórica quanto afetiva, revela certa insegurança sobre o futuro do festejo, pois, segundo o relato a seguir, os jovens não têm demonstrado interesse em participar por não se perceberem fazendo parte do folguedo.

O Terno de Reis prá nós é uma apresentação da religião herdada de nosso avô. Todo ano depois das festa... a missa, sempre terminava com o Terno de Reis. Hoje os "jove" não quer participar. Diz ser coisa de velho. Eu gosto muito. Gosto de festa. Sempre gostei de dançar. To nessa idade e todo ano to aqui. Hoje ficou uma coisa importante para o lugar. Depois que aqui virou quilombola. (Colaborador 1, 86 anos, entrevistado em 2015)

Entre os mais velhos existe uma percepção da perda de entusiasmo dos jovens para dar seguimento à cultura herdada de seus ancestrais. Esta preocupação tem certa razão de ser, posto que são poucos os jovens que mostram interesse em pegar os instrumentos ou "puxar" um samba; outro possível fator é a migração para as grandes cidades em busca de melhores condições de trabalho e educação.

As indumentárias idealizam a visão do sagrado com a bandeira que representa a Trindade e, mais recentemente, outro estandarte foi incluso no conjunto, a bandeira do "Quilombo", correspondendo ao que Wagner (2011) chama de cultura inventiva ao argumentar:

(A cultura)... opera através de nossos formulários, cria em nossos termos, pede emprestadas nossas palavras e conceitos para seus significados e nos recria através dos nossos esforços. (...) Se a nossa cultura é criativa, então as "culturas" que estudamos, como exemplos desse fenômeno dos outros, também devem ser. (Wagner, 2011, p. 16)

Às roupas estão associados significados, designadamente quanto a representações acerca das cores, seja no campo do sagrado ou da cultura local. As indumentárias e as comidas colaboram para a afirmação da identidade quilombola no enfrentamento às ameaças simbólicas e políticas que as comunidades tradicionais vêm sofrendo no atual contexto político brasileiro.

$\mathrm{Na}$ visão da entrevistada que segue, o reconhecimento oficial da comunidade enquanto lugar de quilombo favoreceu um novo olhar sobre o Terno de Reis.

Olha, eu acho que aos poucos, depois que aqui foi conhecido como comunidade quilombola, o terno de reis reviveu. Faz parte da nossa cultura, né? A escola já colocou como atividade da escola. Na Semana da Consciência Negra tem apresentação mirim. Eu mesmo acho isso importante. (Colaboradora 2, 68 anos, entrevistada em 2015) 
Ao perceber esta valorização por parte das atividades decorrentes na escola local, a comunidade também se imbui deste pertencer como parte imaterial do Terno de Reis.

A insegurança em relação ao futuro do Terno de Reis em Nova Esperança decorre do fato de que a modernidade promove a busca dos anseios individuais dos moradores em busca de outras propostas de vida oferecidas pelo mercado externo, ficando o folguedo reservado às apresentações restritas para visitantes efêmeros.

Eu gosto da festa. Todo ano a gente tá aqui. Faço de tudo para não perder. A gente parece que precisa vir aqui. Pena que só posso vir no dia da festa. Temos de trabalhar e aqui não tem oportunidade, mas damos sempre um jeitinho para tá aqui todo ano. O povo, né, nossa família, são resistentes. Não desanimam. Todo ano eles estão aqui. Também acho que às vezes precisa renovar o jeito da festa, senão o povo não vem. (Colaborador 4, 27 anos, entrevistado em 2015)

De acordo com Stuart Hall (2006), as "crises de identidade" resultam das amplas mudanças que ocorrem nas estruturas sociais contemporâneas, com consequentes reconfigurações da identidade cultural.

Quanto mais a vida social se torna mediada pelo mercado global de estilos, lugares e imagens, pelas viagens internacionais, pelas imagens da mídia e pelos sistemas de comunicação globalmente interligados, mais as identidades se tornam desvinculadas - desalojadas - de tempos, lugares, histórias e tradições específicos e parecem "flutuar livremente". (Hall, 2006, p. 43)

A identidade não é inerente ao nascimento, mas construída ao longo de nossa existência a partir das relações construídas e individualizadas pelas narrativas do eu e reelaboradas continuamente na contemporaneidade.

Para Hall (2011, p. 13), "a identidade pode ser construída precisamente com aquilo que falta por meio das diferenças e não fora dela", por isso a identidade torna-se uma "celebração móvel", formada e transformada continuamente em relação às formas pelas quais somos representados ou queremos representar-nos a nós, ao outro e ao lugar a partir de modelos culturais que nos rodeiam.

A identidade é, portanto, um processo interminável de interações entre pessoas que resulta em fronteiras e proximidades em um território cultural, ou seja, construímos identidades em interação com o outro - em contato com a família, a comunidade, a cultura, em espaços diversos - de maneira que adquirimos informações que resultam em subjetividades. Como nos fala Roy Wagner (2011), o homem "é um mediador de coisas, construtor e capaz de 'transformar-se' nas coisas em seu entorno, de integrá-las ao seu conhecimento, ação e ser" (Wagner, 2011, p. 211).

Isto decorre das mudanças ocorridas nas estruturas sociais da pós-modernidade na qual a identidade do sujeito também se modifica pelo seu contato com outras identidades, elaborando culturas híbridas. Para Canclini (1997), a hibridização opera a partir da mescla entre culturas, entre o popular e culto, e entre o tradicional e moderno. 


\begin{abstract}
A hibridação sociocultural não é uma simples mescla de estruturas ou práticas sociais discretas, puras, que existiam em forma separada, e ao combinar-se, geraram novas estruturas e novas práticas. Às vezes isto ocorre de modo não planejado, ou é o resultado imprevisto de processos migratórios, turísticos ou de intercâmbio econômico ou comunicacional. Mas com frequência a hibridação surge do intento de reconverter um patrimônio (uma fábrica, uma capacitação profissional, um conjunto de saberes e técnicas) para reinseri-lo em novas condições de produção e mercado. (Canclini, 1997, p. 113)
\end{abstract}

Entendendo a tradição como o passado persistindo no presente e aceite por quem a recebe, ela perpetuará de geração em geração e, por isso, não é possível concebê-la fora do lugar, pois a mesma está intimamente ligada a um grupo social historicamente e geograficamente situado. Porém, essa tradição não é imóvel, ao contrário, ao longo do tempo os sujeitos vão absorvendo outros hábitos. As culturas estão em constante processo de mobilidade e ação.

Os sujeitos que compõem o Terno de Reis de Nova Esperança deslocam-se continuamente visto estarem em constante vai-e-vem entre a comunidade e outros espaços fora dela. Para Dubar (1997), as identidades são construídas a partir de outras experiências e, por conseguinte, são injetadas na cultura local abrindo possibilidades para outros elementos", pois a "identidade nunca é dada, é sempre construída" (Dubar, 1997, p. 104).

Nesse fluxo de sujeitos que vivenciam experiências diversas, a comunidade de Nova Esperança experimenta ao mesmo tempo continuidade e descontinuidade cultural e étnica do Terno de Reis, pois o mesmo está sendo cada vez mais alimentado por outros elementos que também se retroalimentam.

A identidade acontece na trama das relações culturais impostas pelo deslocamento dos sujeitos na busca de outras oportunidades de sobrevivência. Isto resulta na pluralidade de movimentos culturais e étnicos que entrelaçam-se, reificando a cultura em uma trama contínua entre o presente e passado, onde é preciso haver empatia entre o novo e o velho.

Neste ir e vir, o Terno de Reis se ressignifica para se manter em movimento. Dentre os diversos elementos que envolvem esse ressignificar está o dia da festa, que antes era sempre comemorado no dia seis de janeiro. Atualmente, para atender aos jovens que trabalham fora da comunidade e só podem vir no final de semana, a festa está sendo realizada no primeiro sábado que sucede a data oficial.

O Terno de Reis também tem recebido mudanças no que tange sua musicalidade. Além dos instrumentos tradicionais, atualmente foi inserido o uso do microfone. $\mathrm{O}$ objeto tem, de certo modo, modificado o modo comportamental em volta do festejo, pois o mesmo muitas vezes inibe alguns participantes, o que interfere na espontaneidade inerente ao folguedo.

O que antes se encerrava com o samba de casa em casa, agora é finalizado com uma festa alargada, com direito a banda tocando gêneros musicais ao gosto dos mais jovens, como Arrocha, Brega romântico e Axé. 
Esta abertura ao novo tem como intuito agregar os mais jovens no evento e, assim, garantir sua continuidade visto que muitos jovens partiram para as cidades em busca de melhores condições de vida e depois retornaram, percebendo que esse território é base para a sua identidade.

\section{INCONCLUSAS CONSIDERAÇÕES}

O Terno de Reis de Nova Esperança é um folguedo que contribui para o processo de construção identitária e para a reprodução cultural da comunidade. Os membros expressam satisfação de fazer parte do grupo e são conscientes da importância do evento para a afirmação da história do lugar e, ao mesmo tempo, demonstram preocupação com a baixa participação dos jovens. O mesmo é reconhecido formalmente como patrimônio cultural imaterial da comunidade, enfatizando a importância desta manifestação cultural na autoafirmação dos membros da comunidade quilombola.

É preciso dizer que o Terno de Reis em Nova Esperança é uma representação cultural de cunho religioso. A religiosidade presente na festa não impede a relação com elementos profanos. Na verdade, torna o evento popular e com expressiva participação. Como dizem na comunidade, "termina a reza, fica a resenha". Assim, tudo o que chega de positivo é agregado como valor e isto torna o folguedo alegre e frequentado.

Mediante o exposto, entende-se cultura como experiências adquiridas pelos indivíduos ao caminhar pelo mundo, possibilitando as multiplicidades de saberes permitindo alterar a cultura local e gerar outros elementos identitários, pois a cultura está sempre em mudança. Para Frederick Barth (2000), a cultura é "feita de retalhos e remendos", entendida como parte das tradições culturais e experiências individuais.

A sociedade contemporânea é afetada pelo movimento dos sujeitos, resultando muitas vezes em conflitos de identidades e geracionais. Nesse sentido, caberia às políticas culturais apontar saídas para as tensões e, com isso, possibilitar novos paradigmas para as culturas tradicionais onde estes grupos vejam oportunidades de revitalizar as tradições e constituir com isso resistência aos processos de homogeneização e hegemonia cultural.

Desse modo, as tramas que envolvem o Terno de Reis de Nova Esperança devem ser usadas como caminho para o fortalecimento da identidade local, onde as novas identificações dos sujeitos não sejam vistas como atentado às tradições, mas como elementos redefinidores de sua cultura.

Ao final, salientamos que este artigo não teve a pretensão de dar conta das discussões acerca dos diversos fenômenos que envolve a festividade do Terno de Reis de Nova Esperança. Buscamos apontar as permanências e mudanças de elementos culturais que envolve o folguedo perante o contínuo movimento dos sujeitos que dele participam, na perspectiva de apontar possibilidades de ressignificação do festejo frente os movimentos identitários que a contemporaneidade impõe. A cultura se dá na compreensão do modo pelo qual os homens criam a realidade em que vivem, e do como a realidade pode criar os homens que através dela se fazem existir; que "em certo sentido, a invenção não é absolutamente um processo inventivo, mas um processo de obviação" (Wagner, 2011, p. 240). 


\section{REFERÊNCIAS}

Alberti, V. (2005). Histórias dentro da História. In C. B. Pinsky (Ed.), Fontes históricas (pp. 155-191). São Paulo: Contexto.

Almeida, A. W. B. (2006). Terras de quilombo, terras indígenas, "Babaçuais Livres", "Castanhais do Povo", faxinais e fundos de pasto: terras tradicionalmente ocupadas. Manaus: PPGSCA-UFAM.

Almeida, W. B. (2011). Quilombolas e novas etnias. Manaus: UEA Edições.

Arruti, J. M. (2006). Mocambo: Antropologia e História do processo de formação de quilombola. Bauru: Edusc.

Barth, F. (2000). O guru, o iniciador e outras variações antropológicas. Rio de Janeiro: Contra Capa Livraria.

Dubar, C. (1997). Para uma teoria sociológica da identidade. In A socialização (pp. 133- 156). Porto: Porto Editora.

Canclini, N. G. (1997). Culturas híbridas: estratégias para entrar e sair da modernidade. São Paulo: Edusp.

Gonçalves, M.C.S. (2008). Folias de reis: o eco da memória na (re)construção da performance e identidade dos foliões em João Pinheiro, estado de minas gerais. IV Enecult - Encontro de Estudos Multidisciplinares em Cultura (p. 6). Universidade Federal da Bahia. Salvador, Brasil.

Gusmão, N. M. M. de (1995). Terra de pretos, terra de mulheres. Terra, mulher e raça num bairro rural negro. Brasília: Fundação Cultural Palmares.

Gusmão, N. M. M. de. (1979). Campinho da independência: um caso de proletarização caiçara. Dissertação de Mestrado, Pontifícia Universidade Católica, São Paulo, Brasil.

Hall, S. (2006). A identidade cultural na pós-modernidade. Rio de Janeiro: Editora DP\&A.

Hall, S. (2011). Quem precisa de identidade? In T. T. Silva (Ed.), Identidade e diferença (pp. 103-132). Petrópolis, RJ: Vozes.

Queiroz, R. da S. (1983/2006). Caipiras negros no Vale do Ribeira: um estudo de antropologia econômica. São Paulo: EDUSP.

Meihy, J. C. S. B. (1998). Manual de história oral. São Paulo: Loyola.

Moura, C. (1981). Rebeliões da senzala: quilombos, insurreições, guerrilhas. São Paulo: Editora Ciências Humanas.

Munanga, K. \& Gomes, N. L. (2006). O negro no Brasil de hoje. São Paulo: Editora Global.

Pergo, V. L. Os rituais na folia de reis: uma das festas populares brasileiras. Retirado de http://www.dhi.uem.br/ gtreligiao/pdf/st1/Pergo,\%20Vera\%2oLucia.pdf.

Rios, S. (2006). Os cantos da festa do reinado de Nossa Senhora do Rosário e da Folia de Reis. Sociedade e Cultura, 9(1), 65-76.

Wagner, R. (2011). A invenção da cultura. São Paulo: Cosac Naify. 


\section{NOTA BIOGRÁFICA}

Cledineia Carvalho Santos é Mestre em Cultura e Sociedade pela Universidade Federal da Bahia, especialista em ensino de Língua Portuguesa pela Universidade Estadual do Sudoeste da Bahia, Licenciada em Letras pela mesma universidade e Licenciada em História, pela Universidade do Estado da Bahia. É membro do grupo de pesquisa em Mídia e Etnicidade - Etnomídia da Universidade Federal da Bahia. Atua como professora da Educação básica.

ORCID: http://orcid.org/oooo-0003-4446-6913

Email: keucarvalho@yahoo.com.br

Morada: Universidade Federal da Bahia. Av. Adhemar de Barros, s/nº - Ondina, Salvador - BA, 40170110 , Brasil

\section{Submetido: 14.05.2019}

Aceite: 23.09.2019 